\title{
REFLEXIONES SOBRE LA TRADICIÓN CONSERVADORA EN LA TEORÍA DEL DERECHO
}

\begin{abstract}
hora que el año del bicentenario llega a su fin, parece oportuno preguntarnos por el lugar que ocupa la tradición conservadora en la teoría jurídica. En otras palabras, cómo una teoría del Derecho auténticamente conservadora aborda, o debería abordar, los problemas planteados por la Revolución francesa.
\end{abstract}

Antes que nada debo decir que yo no considero ninguna teoría del Derecho como «pura», en el sentido de que pueda verse como algo aislado de las aspiraciones políticas de los diversos grupos sociales. En efecto, yo veo la teoría del Derecho en gran medida como un instrumento útil para la teoría política, con el fin de articular de manera convincente propuestas de poder dentro del Estado y, podríamos añadir, entre los Estados (que de modo similar se encuentran en lucha unos con otros). Para decirlo con menos crudeza, bastaría con aludir a la inutilidad de los intentos por aislar cualquier rama de estudio (Geistewissenschaften) de la influencia filosófica.

Por lo tanto, se infiere automáticamente que yo no puedo dejar de ver una conexión muy estrecha entre la doctrina del llamado Estado de Derecho (Rule of Law, Rechtsstaat), por un lado, y las aspiraciones de la burguesía liberal que pueden remontarse a las convulsiones de 1789 y a toda la Ilustración, por el otro. La teoría conservadora moderna, tal como yo la veo, surgió como respuesta a esta amenaza, como respuesta a los peligros y a la destrucción efectiva que las teorías iusnaturalistas radicalizadas representaron para la civilización europea tradicional, a las declaraciones de derechos humanos, a la libertad e igualdad y, finalmente, a la democracia. Así pues, la teoría conservadora comenzó como una contrarrevolución; suministró las excusas teóricas para el terror blanco. A lo largo de todas las revoluciones posteriores hasta e incluida la rusa de 1917, la legitimidad de los tronos, el statu quo, el viejo orden y todos sus privilegios, fueron el caballo de batalla común de teóricos y es- 
tadistas conservadores como de Maistre y, en mi opinión, Donoso Cortés.

Pero, por supuesto, estos conservadores estaban luchando por una causa perdida. El poder cambió de manos gradualmente durante el siglo XIX, y cada vez más, irónicamente, «liberales» como Guizot y Thiers se encontraron en la vieja posición del ancien régime de intentar bloquear la reforma radical, por la que quien clamaba era ya por entonces el proletariado, amenazando las instituciones y las posiciones de la burguesía capitalista. $\mathrm{Su}$ teoría correspondiente se había hecho entre tanto más positivista y menos idealistamente iusnaturalista, aunque después de la segunda guerra mundial ha habido un renacimiento del pensamiento iusnaturalista en ciertos sectores. Todavía hoy nos encontramos en cierto modo en una situación de difícil equilibrio entre liberalismo y socialismo. El conservadurismo propiamente dicho parece haber desaparecido, junto con su teoría.

En cierto modo la vieja tradición ha sido continuada por el pensamiento iusnaturalista católico, que no se ha dejado influenciar por el por otra parte dominante movimiento realista, ni siquiera en Escandinavia. También puedo añadir aquí que, de manera análogamente realista, pensadores como Kelsen, que ciertamente no pueden considerarse conservadores según mi interpretación, han puesto de manifiesto de modo convincente los presupuestos ideológicos liberales que se ocultan tras las concepciones y construcciones aparentemente técnicas de la ciencia jurídica positivista, como el Gesetzbuch alemán de 1898.

En este contexto de historia de las ideas, intentaré rastrear la escurridiza pista que ha seguido la tradición conservadora, tomando el año 1789 como punto de partida para llegar hasta nuestros días. Me refiero a Edmund Burke y al movimiento romántico, especialmente tal como fue desarrollado por los científicos alemanes. Porque aquí no sólo está la Reacción y la Santa Alianza, la policía secreta de Metternich y el rutinario Beamtenstaat; es también la Freiheit teutónica, o mejor dicho, alemana, como opuesta a la liberté de la Revolución francesa; un idealismo completamente distinto, que comprende todo el Volk.

Sería un error, creo yo, decir que Hegel llegó a captar este movimiento, esta revuelta contra las máximas de la Ilustración, esta reacción contra la Revolución; porque él lo plasmó en un sistema filosófico, lo intelectualizó, en suma, lo puso al servicio del Beamtenstaat, que, como hemos visto, de todas formas fue haciéndose cada vez más liberal, al menos después de 1848 (la unificación alemana de Bismarck cambió pocas cosas a este respecto). La teoría conservadora rehuye los sistemas, e intenta en 
su lugar entender la vida intuitivamente, en una especie de modo holístico. No tiene en gran estima el poder de razonamiento del individuo, igual que tiene miedo de sus emociones, desatadas en masse. Pero, ¿cómo debe lograrse la incorporación del individuo a la comunidad, ganarse su lealtad, y explicarla «teóricamente»? Hasta ahora, la coacción y/ o el autointerés habían sido las únicas respuestas. No es de extrañar que de tales modos básicamente racionalistas de pensar no hubiera surgido un espíritu público. La idea del contrato social, desde luego, había sido durante mucho tiempo el instrumento al uso. Rousseau había intentando aplicarla a usos más fructíferos; su estilo era sin duda romántico, pero su idealismo era antiautoritario; la volonté générale había resultado ser irrealizable, y el esquema en su conjunto potencialmente despótico.

Burke, aunque se le pueda citar en sentido contrario, rompió con toda esta línea de pensamiento que durante tanto tiempo había reducido la sociedad a un mero contrato, a «un trato entre socios en el comercio de pimienta y café, percal o tabaco, o algún otro interés tan bajo; un trato que se adopta para lograr un propósito temporal y se disuelve al antojo de las partes». Por el contrario, de Burke puede decirse con justicia que idealizó la autoridad, pero no de modo que se le pueda hacer responsable de los abusos en los que esta nueva concepción del Estado desembocó más tarde. «La sociedad», continúa diciendo en su famoso panfleto Reflexiones sobre la Revolución en Francia (1790),

«ha de ser vista con una veneración distinta; porque no es una asociación para cosas subordinadas únicamente a una vulgar existencia animal de carácter temporal y perecedero. Es una asociación para todo el saber; una asociación para todo el arte; una asociación para cada virtud, y para toda perfección. Como los fines de tal asociación no pueden alcanzarse en muchas generaciones, se convierte en una asociación no sólo entre quienes viven, sino entre quienes viven; quienes han muerto, y quienes van a nacer.»

Con estas conocidas palabras se inauguró una nueva era en el pensamiento político. Se había dado la señal para el avance general de las teorías organicistas del Estado. Y, como dije antes, fue en Alemania donde sucedió casi todo esto. Adam Müller se refirió al Estado con este mismo espíritu, como algo más que una casa en la que se puede entrar y salir a placer. Al principio, la recepción del pensamiento de Burke tuvo lugar a través de la Universidad de Göttingen y de la llamada Escuela de Hannover, 
aunque Gentz, que tradujo a Burke al alemán, hizo un uso más reaccionario que romántico de sus ideas en nombre de la corte de Viena, que por aquel entonces estaba en el proceso de transformar a Austria de la Aufklärung al Beamtenstaat con incluso menos de esa fase romántica de transición que en cualquier otra parte del decrépito imperio alemán.

Pero es quizá con la reconstrucción de Prusia con lo que mejor puede asociarse la transición de la Ilustración al período romántico, aunque éste durará poco tiempo. También Prusia había sido en cierto modo un centro de la Ilustración, igual que después la actitud subsiguiente se reflejó a través de sus universidades y del romanticismo berlinés, constituyendo, se podría decir, la segunda ola después de Hannover. Lo primero que nos viene a la cabeza es la obra de reforma y oposición a los franceses, brillantemente llevada por von Stein: la agitación nacionalista expresada por Fichte, Arndt y Kleist, por nombrar sólo a algunos. El ideal de Stein había sido el de una libertad corporativa que debía conferirse a las estructuras muertas del antiguo Ständestaat, con lo que quedaría investido de un nuevo espíritu idealista de servicio, de espíritu público, de subordinación y sacrificio voluntariamente ofrecidos. De muchas formas y en muchos campos Stein fracasó en su intento de remodelar las instituciones alemanas según patrones ingleses; su sucesor, Hardenberg, fue incluso menos entusiásticamente romántico; $\mathrm{y}$, como ya he apuntado, fue un experimento de corta duración.

Pero en el ejército este nuevo espíritu sí que arraigó. El Freicorps tuvo un éxito arrollador en 1813-15 junto a las unidades regulares, y con su esprit de corps recién adquirido el nuevo ejército y sus líderes iban a convertirse en una élite, el pivote en torno al cual giraría el Estado. Esta situación permitió, y se vio acentuada por, sucesivas reformas relativas al reclutamiento. Gneisenau y Scharnhorst sentaron las bases de la obra de von Roon en la década de 1860, proporcionando finalmente al poder lo que éste necesitaba: un ejército moderno de reclutamiento obligatorio con el que poder librar una guerra moderna de aniquilación (las ideas de Clausewitz llevadas a cabo por Moltke), lo que a su vez dio origen a la Alemania de Bismarck.

Pero no adelantemos acontecimientos. En 1814, con la reacción comenzando a asentarse, pero siendo todavía predominante el clima de opinión romántico, el ámbito del Derecho se vio directamente afectado. Napoleón ya había introducido sus códigos burgueses-revolucionarios en Renania y en Westfalia, mostrando a la burguesía alemana cómo podrían «liberarse» y modernizarse, emanciparse cívicamente, como si ello pudiera lograrse de la 
misma manera en que los ejércitos revolucionarios habían triunfado en la década de 1790 sobre las formaciones mecánicamente entrenadas que las coaliciones habían sido capaces de reunir y que sólo se mantenían unidas mediante la coacción. Esta última actitud de guiar los comportamientos de la gente era también la que subyacía al Landrecht prusiano de 1794, la herencia del despotismo ilustrado de Federico, que contenía miles de normas detalladísimas. El código austríaco, que también había sido recientemente introducido, era más moderno y abstracto. Por lo demás, en el Derecho civil predominaba una complicada mezcla de fuentes del Derecho: costumbres del lugar; Gemeines Recht; diversos elementos romanos más o menos actualizados; así como toda suerte de curiosas disposiciones administrativas y de viejas adiciones in casu con sabor autoritario, que variaban de un principado a otro, siendo todas en general Derecho no escrito.

Este era el contexto de la célebre resistencia de Savigny al código que por aquel entonces se había propuesto para Alemania (o, para ser más precisos, principalmente para aquellas partes que hasta entonces habían estado sin código). Fue en parte la típica reacción del aristócrata del viejo orden, que despreciaba y se atrevía a contradecir las aspiraciones burguesas, expresadas de forma igualmente típica por Thibaut, su adversario. Pero, como ya hemos señalado, los códigos también podían destinarse a un «buen uso» al servicio de los intereses de la reacción emergente; podían hacer un buen trabajo para el Beamtenstaat de Hegel; en suma, forzar y dar marcha atrás al reloj. No obstante, la controversia era algo más que eso. Savigny también era en cierto modo un romántico; von Humboldt le había otorgado una cátedra de Derecho en la Universidad de Berlín, que había sido fundada en 1810 como parte integrante de las medidas de Stein para revigorizar al Estado prusiano, para reformarlo atrayendo a todos sus súbditos, invitándoles a servir al Estado no menos que a sus Bürger. La concepción organicista y romántica del Estado integró a todos los órdenes en un tipo peculiar de comunidad, una Volksgemeinschaft, que, como ya hemos visto en el caso de Burke, era verdaderamente una entidad super-individualista, hipostasiada, que comprendía un Volk particular a través de sus diferentes edades y generaciones, reteniendo una especie de carácter permanente. Esta es la raíz de la teoría del Volksgeist en la que Savigny basó su pensamiento jurídico; los materiales para la reforma jurídica deben, pues, tomarse de la propia historia del pueblo, y solamente serviría aquello que ha crecido orgánicamente. Era, en suma, un problema histórico, una cuestión teórica, perfectamente adaptable a usos políticos. Y 
así fue usada, como sabemos, con el resultado de que el Gesetzbuch no se introdujo hasta ochenta y cinco años más tarde. Quizá quepa añadir que el propósito de esta sofisticada teorización acerca del Volk era, por supuesto, ofrecer una alternativa tanto al liberalismo (que habría atomizado el todo) como al socialismo (que lo habría dividido según diferencias de clase), aunque en la época de Savigny el liberalismo representaba, como ya dije, la principal amenaza.

La teoría de Savigny y de la Escuela Histórica en general sigue siendo enormemente peculiar e imprecisa, pero es desde luego genuina teoría jurídica conservadora. Típico, y se podría decir que extraño, es su firme énfasis, en la Beruf unserer Zeit für Gesetzgebung und Rechtswissenschaft (1814), en la idea de que el origen último, directo e inescrutable del Derecho, está en el pueblo. El lo llama el «elemento político». Es una variación sobre el tema romántico del entendimiento intuitivo. Pero, al mismo tiempo, a Savigny le preocupa igualmente subrayar la necesidad y el enorme valor de la «jurisprudencia técnica», que ésta sea científica, aunque consista en una remodelación de materiales. Aquí, en realidad, los materiales con los que él y sus colegas trabajaron eran romanos, no germánicos. En este sentido, Savigny fue un típico «elegante jurista latino», un aristócrata también en su capacidad profesional, que finalmente se encontró en un campo diferente al de los normalmente menos grandiosos Germanisten. Y así, aunque Gierke, en su resistencia al Gesetzbuch, reproduce muchos de los argumentos de Savigny, éste último permanece mucho más vago y en cierto sentido más infiel con respecto al fundamento völkisch de su teoría. Debemos recordar también que las distinciones de clase, como ya se ha sugerido, tendían a unir las aspiraciones burguesas a las «Germanísticas», tanto política como científicamente, y que era imposible, incluso en la controversia Savigny-Thibaut, mantener estos campos separados. Y parecen haberse confundido cada vez más durante el siglo XIX. Siendo más críticos, nuestra conclusión es que la teoría que la teoría de Savigny muestra la inevitabilidad de apuntalar una teoría «pura» del Derecho con elaboraciones filosóficas (preferiblemente explícitas), al menos cuando llegamos a concepciones tan fundamentales en jurisprudencia como el Estado y -por seguir usando el alemán- el Volk; en el caso de Savigny se deja demasiado a la interpretación y a la especulación.

Para finalizar, señalaré brevemente el papel jugado por Gneist, y discutiré el destino de la moral tradicional en el Estado orgánico (especialmente cuando es concebido en tono völkisch) 
y en nuestra era moderna y científica. Empezaré trayendo de nuevo a colación al ejército. Antes aludí a él como un elemento triunfante de la reforma romántica en el caso de Prusia. Con esa caracterización yo tenía en mente la búsqueda de instituciones históricas a las que se pudiera dar un nuevo modo de vida orgánica, que pudieran servir como puntos de referencia para un nuevo tipo de espíritu público o de idealismo, que venga de los corazones de quienes los «pueblan». Y es exactamente desde este punto de vista desde el que el ejército es una corporación tan importante en un Estado orgánicamente entendido. El ejército fomenta, o al menos debería hacerlo, un sentido de pertenencia, de buena disposición para servir y en última instancia dar la vida por el conjunto y por los demás hombres de la unidad en cuestión, mediante el cual también se adquiere una especie de profundidad moral. Y, además, sirve como el instrumento que da cumplimiento a esa especial vocación histórica con la que el Volk ha sido investido. El ejército es en este sentido el Estado y el Volk. Y una filosofía cultural adecuadamente formulada disculparía fácilmente cualquier embarazoso exceso contra la moral tradicional, el Derecho Internacional Público, u otras restricciones similares al uso de la fuerza, simplemente ignorando tales controles, apelando una vez más a lo que es bueno, mejor dicho, necesario, para el Volk (la teoría de la guerra total).

Gneist era demasiado chapado a la antigua para esa clase de embrutecimiento, y de todas formas el ejército no era asunto suyo. Al igual que Stein y los hannoverianos, él estaba fascinado por la vida constitucional de Inglaterra expresada en su historia, y allí buscó medios a través de los cuales el amenazante deslizamiento hacia la democracia pudiera ser detenido también en Alemania. Además, él era otro aristócrata. En Inglaterra, sostuvo Gneist, ese espíritu público se había conseguido mediante corporaciones locales (autogobierno), que finalmente constituyeron el tejido social que mantuvo el statu quo aristocrático. Desde la guerra civil se había evitado los ejércitos grandes, permanentes; eran vistos como instrumentos de opresión, de poder centralizado. La gran contribución de Gneist a la teoría conservadora radica en su acentuación del papel de las obligaciones asumidas en el contexto del mencionado tejido (cuyo cumplimiento produjo las lealtades y afectos hacia la comunidad por las que los conservadores, aunque fuera por su propia seguridad y bienestar, se habían interesado mucho más que los liberales), y sólo con el tiempo, de los «derechos». De modo que era ir por el mal camino empezar a exigir derechos de voto y cosas por el estilo, que sólo podían servir para destruir esos tejidos. En su 
lugar, se debía invitar a esta gente a servir en el seno de los tejidos, a probarse a sí mismos antes de que se pudiera empezar a hablar de un derecho positivo a tener voz. Es el «pequeño pelotón» de Burke, aunque más elaborado: la integración orgánica, y el anteponer el cumplimiento de las obligaciones al discurso de los derechos, serían las nociones clave.

El moderno ejército de reclutamiento obligatorio, al que aludí un poco antes, es una buena ilustración del pensamiento Gneisteano. En Suecia fue utilizado por conservadores como el historiador Harald Hjärne, al vincular la cuestión del sufragio universal con la de la reforma militar: cumpliendo el servicio militar se obtenía el derecho al voto. Pero, antes de eso, no sólo se había recreado y fortalecido un órgano poderoso, un bastión de estabilidad en el Estado; el ejército también habría conseguido hacer de los trabajadores unos ciudadanos leales (inofensivos). ¿No demostró el estallido de la primera guerra mundial que la materialista solidaridad de clase había sido más débil que la lealtad al Volk?

Resulta más difícil detectar el elemento de idealismo que está en la raíz de este esquema conservador, según lo ven algunos, cuando pasamos a considerar el desarrollo del poderío naval como prerrequisito de una política exterior imperialista. Sólo se me ocurre el caso de Kipling, puesto que Kidd y Seeley eran liberales (compárese el libro de aquél, La evolución social, con el de éste, El crecimiento de la política británica). Factores naturales podían hacer necesario que un Estado orgánico apostara también por el poderío marítimo. La obra de Ratzel Geopolítica fue la que proporcionó la base teórica para el pensamiento conservador en su versión moderna, una ideología en conjunto más agresiva, menos idealista, y esencialmente nacionalista. También hubo una orientación similar dentro del campo liberal; quizá podamos mencionar aquí a Heinrich von Treitschke. El recurso al Volk adquiere un tinte más basto, con menos de esa paternal sabiduría mundana del aristócrata que todavía puede detectarse en el lenguaje de los defensores de la Democracia Tory, que a su vez puede remontarse al movimiento de Disracli Joven Inglaterra, sumamente romántico, allá por la década de 1840. Pero esto no era más que otro embrutecimiento que no tenía que sorprender: era sólo una oportuna adaptación al nivel de debate en una era de sufragio universal y de Metrópolis como la que reflejó Fritz Lang.

Era también una era de «progreso», ante el que los conservadores siempre se habían mostrado escépticos. ¿Cuál debería ser su postura? Algunos se embarcaron en una vehemente crítica 
cultural, y se convirtieron en Konservative Revolutionäre o socialistas, como Mussolini en Italia y sir Oswald Mosley en Inglaterra. Kjellén, seguidor de Ratzel en Suecia y muy admirado en Alemania, quería revitalizar a la derecha por medios «völkisch». Ante el ascenso de los nacionalistas en Alemania, Kjellén había adoptado la idea de enlazar las dos líneas de pensamiento ideológico más poderosas del siglo XIX como la solución conservadora a los problemas del XX. En 1914, Kjellén había tomado partido abiertamente por Alemania, porque representaba el orden y una concepción de un Estado fuerte como el único medio para vencer la falsa libertad y el excesivo individualismo de 1789. Líder de un grupo de jóvenes conservadores, desafiante de la disciplina de partido, y seguidor de la ya por entonces desgastada idea del Estado orgánico, en oposición directa a la ciencia política tradicional y legalista, Kjellén es un buen ejemplo de la exasperación de los modernos conservadores en una era en la que todos los valores y virtudes parecen en cierto modo efímeros. De la misma forma muchos conservadores en Alemania aclamaron inicialmente la llegada del nazismo. Un ejemplo que viene al caso es el de Walther Merk. Merk pensó que los nazis iban a restablecer un Ständestaat autoritario que salvaguardaría materialmente esa conexión con la moral tradicional que muchos como él vieron expresada en la noción de Germanische Freiheit. Ni siquiera Kjellén hubiera imaginado una ruptura completa con la tradición cultural occidental (y su concepción del Volk como un colectivismo socialista moderno no tenía teorías raciales como una base esencial). Carl Schmitt y Karl Larenz fueron más cínicos; el fascismo, en el sentido amplio de Nolte, era claramente el camino equivocado para la teoría conservadora. La cuestión es si el giro tras la segunda guerra mundial hacia un discurso liberal de los derechos, de reducir la esfera de influencia del Estado, y de promover las organizaciones internacionales, aunque resulte un cambio comprensible, no queda incluso más lejos de su propio objetivo, al menos como expresión auténtica del alma conservadora.

(Trad. de Juan A. Pérez Lledó) 